\title{
Normative Data for Gait Speed and Height Norm Speed in $\geq 60$-Year-Old Men and Women
}

This article was published in the following Dove Press journal:

Clinical Interventions in Aging

\author{
Mario Kasovićl,2 \\ Lovro Štefan' \\ Andro Štefan' \\ 'Faculty of Kinesiology, Department of \\ General and Applied Kinesiology, \\ University of Zagreb, Zagreb, I0000, \\ Croatia; ${ }^{2}$ Faculty of Sports Studies, \\ Department of Sport Motorics and \\ Methodology in Kinanthropology, \\ Masaryk University, Brno, 62500, Czech \\ Republic
}

Purpose: To determine normative data for gait speed and height-normalized gait speed in community-dwelling older men and women.

Materials and Methods: In this cross-sectional study, we recruited 565 men and women aged $\geq 60$ years old. Age was calculated from the date of birth and further classified into four categories: (1) 60-65 years, (2) 66-70 years, (3) 71-75 years and (4) $\geq 76$ years. Gait speed was assessed by a pressure platform (ZEBRIS, Munich, Germany) in meters per second (m/ s). Height and weight were objectively measured. Height-normalized gait speed was calculated by dividing gait speed by height. We created the 20th, 40th, 60th and 80th percentile curves for both outcome measures using Cole's Lambda (L), Mu (M) and Sigma (S) method. Results: Mean gait speed and height-normalized gait speed was 1.24 (standard deviation 0.28 ) and $0.75(0.17)$. Significant age-related decline in gait speed for both sexes was observed $(p<0.001)$. Being a woman $(\beta=-0.09, p<0.001)$, being older $(\beta=-0.02, p<$ $0.001)$ and having higher body mass index values $(\beta=-0.02, p<0.001)$ were significantly associated with slower gait speed.

Conclusion: Gait speed significantly declines with age in both older men and women. Providing normative data can be used in screening and monitoring "slow" walkers to prevent from foot pain and higher risk of falls.

Keywords: walking, elderly, standards, ageing

\section{Introduction}

Gait speed is a significant determinant of health. ${ }^{1}$ In older adults, evidence suggests that gait speed can predict several adverse outcomes, including mortality, ${ }^{2}$ functional dependence, ${ }^{3}$ well-being, ${ }^{4}$ cognitive decline ${ }^{5}$ and frailty. ${ }^{6}$ Thus, health-related benefits of gait speed are of great importance for preserving a successful aging and being independent.

In order to compare pathological with normal gait speed, it is crucial to establish reference-based data to be interpretable. To date, several studies from United Kingdom, ${ }^{7,8}$ Canada, ${ }^{9,10}$ Sweden, ${ }^{11}$ United States, ${ }^{1,12,13}$ Japan $^{14-16}$ and Australia ${ }^{17}$ have examined and provided age-related changes and normative values for gait speed. In general, the aforementioned studies have observed that gait speed significantly declines with age in both sexes. However, no study has reported such data regarding Croatian older adults. It is estimated that the percentage of older people will exceed the number of young by $2050 .{ }^{18}$ In Croatia, $25.0 \%$ of the population is aged $\geq 65$-year-old. ${ }^{19}$ Thus, specific normative data and graphical curves for gait speed should help health-related professionals in screening functional dependence and monitoring the effectiveness of rehabilitative interventions. ${ }^{17}$
Faculty of Kinesiology, Department of General and Applied Kinesiology, University of Zagreb, Horvaćanski Zavoj

15, Zagreb, I0000, Croatia

Tel +385-09891-77-060

Email lovro.stefan1510@gmail.com 
Therefore, the main purpose of the study was to establish sex- and age-normative data for gait speed and heightnormalized gait speed in older adults.

\section{Materials and Methods Study Participants}

In this cross-sectional study, we recruited communitydwelling older men and women aged $\geq 60$ years who were part of the Society for Sport Recreation for older people in the city of Zagreb. First, we briefly described the main aims, hypotheses and practical implications of the study. The Society has approximately 4.000 registered users. By using the confidence level of $95 \%$ and confidence interval of 4 , our estimated sample size was 522 . We increased the sample size, due to possible missing data. To be included in the study, participants needed to be: (1) $\geq 60$ years of age, (2) without gait impairments or using an aid to walk, (3) without chronic diseases which may affect gait patterns and (4) without cognitive problems. Our final sample included 565 older men and women. Basic descriptive statistics of the study participants are presented in Table 1. Before the study began, each participant had signed a written informed consent to participate in the study and agreed that the data could be used for scientific purposes. Data collection was anonymous and in accordance with the Declaration of Helsinki (1964). Procedures in the study were approved by the Ethical Committee of the Faculty of Kinesiology.

\section{Gait Speed}

To measure gait speed, we used a pressure platform (ZEBRIS company, FDM; GmbH, Munich, Germany; number of sensors: 11,264; sampling rate: $100 \mathrm{~Hz}$; sensor area: $149 \mathrm{~cm} \times 54.2 \mathrm{~cm}$ ). The procedure of previously published papers related to this topic was followed. ${ }^{20} \mathrm{In}$ brief, the walkway was $10.5 \mathrm{~m}$ in length $(1.5 \mathrm{~m}$ platform and $4.5 \mathrm{~m}$ custom-designed dense material before and after the platform). The protocol consisted of a set of instructions to participants to walk at a preferred speed and to look straightforward across the platform being barefoot and without targeting the platform. When the participants finished walking across a $10.5 \mathrm{~m}$ walkway, they needed to turn around for $180^{\circ}$ and continue to walk over the platform until they reached the end of the walkway. The aforementioned protocol was repeated once again with a total of four trials across the platform. If we detected obvious gait deviations, we discarded the trials and
Table I Basic Descriptive Statistics of the Study Participants (N $=565$ )

\begin{tabular}{|c|c|c|c|}
\hline \multirow[t]{2}{*}{ Study Variables } & $\begin{array}{l}\text { Men }(N= \\
162)\end{array}$ & $\begin{array}{l}\text { Women (N } \\
=403)\end{array}$ & \multirow[t]{2}{*}{$\begin{array}{l}p \text {-value for } \\
\text { Trend }\end{array}$} \\
\hline & $X(S D)$ & $X(S D)$ & \\
\hline $\begin{array}{l}\text { Height }(\mathbf{c m}) \\
60-65 \text { years } \\
66-70 \text { years } \\
7 I-75 \text { years } \\
\geq 76 \text { years }\end{array}$ & $\begin{array}{l}174.5(6.0) \\
174.8(5.7) \\
17 \mid .9(4.9) \\
172.8(7.0)\end{array}$ & $\begin{array}{l}162.0(6.6) \\
161.6(5.5) \\
160.1(5.6) \\
160.0(5.7)\end{array}$ & $<0.001$ \\
\hline $\begin{array}{l}\text { Weight } \mathbf{( k g )} \\
60-65 \text { years } \\
66-70 \text { years } \\
7 I-75 \text { years } \\
\geq 76 \text { years }\end{array}$ & $\begin{array}{l}85.3(9.8) \\
84.2(11.1) \\
80.4(8.8) \\
84.5(10.9)\end{array}$ & $\begin{array}{l}72.1(13.6) \\
69.0(10.9) \\
69.0(10.8) \\
67.5(12.4)\end{array}$ & $<0.001$ \\
\hline $\begin{array}{l}\text { Body mass index } \\
\left(\mathbf{k g} / \mathbf{m}^{\mathbf{2}}\right) \\
60-65 \text { years } \\
66-70 \text { years } \\
71-75 \text { years } \\
\geq 76 \text { years }\end{array}$ & $\begin{array}{l}28.1(3.5) \\
27.5(3.3) \\
26.9(2.7) \\
28.3(3.6)\end{array}$ & $\begin{array}{l}27.3(4.5) \\
26.4(4.2) \\
26.9(3.9) \\
26.2(4.3)\end{array}$ & 0.091 \\
\hline $\begin{array}{l}\text { Gait speed }(\mathrm{m} / \mathrm{s}) \\
60-65 \text { years } \\
66-70 \text { years } \\
71-75 \text { years } \\
\geq 76 \text { years }\end{array}$ & $\begin{array}{l}\mathrm{I} .40(0.18) \\
\mathrm{I} .3 \mathrm{I}(0.19) \\
\mathrm{I} .19(0.18) \\
\mathrm{I} .10(0.23)\end{array}$ & $\begin{array}{l}\mathrm{I} .36(0.23) \\
\mathrm{I} .22(0.30) \\
\mathrm{I} . \mathrm{II}(0.25) \\
0.98(0.30)\end{array}$ & $<0.001$ \\
\hline $\begin{array}{l}\text { Height- } \\
\text { normalized }(\mathrm{m} / \mathrm{s}) \\
60-65 \text { years } \\
66-70 \text { years } \\
71-75 \text { years } \\
\geq 76 \text { years }\end{array}$ & $\begin{array}{l}0.80(0.11) \\
0.75(0.12) \\
0.69(0.10) \\
0.63(0.14)\end{array}$ & $\begin{array}{l}0.84(0.15) \\
0.75(0.18) \\
0.69(0.15) \\
0.61(0.20)\end{array}$ & $<0.001$ \\
\hline
\end{tabular}

repeated the protocol. Height and weight were objectively measured by using anthropometric kit and digital scale.

\section{Data Analysis}

Basic descriptive statistics are presented as mean ( $\mathrm{x}$ ) and standard deviation (SD). Differences between sex (men vs women)- and age-specific (60-65 years, 66-70 years, 71-75 years and $\geq 76$ years) variables were calculated by univariate analysis of variance (ANOVA). We used Cole's Lambda, Mu and Sigma (LMS) method, in which the optimal power to obtain normality is summarized by a smooth (L) curve and trends in the mean (M) and coefficient of variation (S) are similarly smoothed. ${ }^{21}$ Next, all three curves (L, $M$ and $S$ ) are summarized based on the power of age-specific Box-Cox power 
Table 2 Normative Data for Gait Speed and Height-Normalized Gait Speed in the Study Participants $(\mathrm{N}=565)$

\begin{tabular}{|c|c|c|c|c|c|c|c|}
\hline Measure & Sex & Age & $\mathbf{N}$ & $\mathbf{P 2 0}$ & P40 & P60 & P80 \\
\hline \multirow[t]{4}{*}{ Gait speed $(\mathrm{m} / \mathrm{s})$} & Men & $60-65$ years & 59 & 1.23 & 1.33 & 1.43 & 1.53 \\
\hline & & $66-70$ years & 49 & 1.19 & 1.27 & 1.34 & 1.42 \\
\hline & & $7 I-75$ years & 27 & 1.0 & 1.17 & 1.27 & 1.32 \\
\hline & & $\geq 76$ years & 27 & 0.89 & 1.04 & 1.13 & 1.27 \\
\hline \multirow[t]{4}{*}{ Height norm speed } & & $60-65$ years & 59 & 0.71 & 0.77 & 0.82 & 0.89 \\
\hline & & $66-70$ years & 49 & 0.67 & 0.73 & 0.76 & 0.89 \\
\hline & & $7 I-75$ years & 27 & 0.59 & 0.67 & 0.73 & 0.78 \\
\hline & & $\geq 76$ years & 27 & 0.50 & 0.59 & 0.68 & 0.76 \\
\hline \multirow[t]{4}{*}{ Gait speed $(\mathrm{m} / \mathrm{s})$} & Women & $60-65$ years & 164 & 1.21 & 1.35 & 1.46 & 1.54 \\
\hline & & $66-70$ years & 103 & 0.99 & 1.22 & 1.30 & 1.45 \\
\hline & & $7 I-75$ years & 83 & 0.88 & 1.00 & 1.16 & 1.37 \\
\hline & & $\geq 76$ years & 53 & 0.72 & 0.83 & 1.01 & 1.27 \\
\hline \multirow[t]{4}{*}{ Height norm speed } & & $60-65$ years & 164 & 0.73 & 0.84 & 0.89 & 0.96 \\
\hline & & $66-70$ years & 103 & 0.61 & 0.75 & 0.81 & 0.91 \\
\hline & & $7 I-75$ years & 83 & 0.57 & 0.63 & 0.73 & 0.83 \\
\hline & & $\geq 76$ years & 53 & 0.45 & 0.53 & 0.65 & 0.78 \\
\hline
\end{tabular}

transformations for normalizing the data. Smoothed curves were presented for the 20th, 40th, 60th and 80th percentiles and further categorized as "very slow" ( $<20$ th), "slow" (20th-40th), "average" (40th-60th), "fast" (60th80 th) and "very fast" (>80th) gait speed. ${ }^{16}$ Heightnormalized gait speed was calculated by dividing gait speed with body height. Multiple regression analysis with the coefficient of correlation $(r)$ and determination $\left(r^{2}\right)$ was used to calculate the associations between sex, age and body mass index with gait speed. The $p$-value in Table 1 represents the general level of statistical computation. All analyses were performed in Statistical Packages for Social Sciences version 23.0 (SPSS Inc., Chicago, Illinois, USA).

\section{Results}

Basic descriptive statistics are presented in Table 1. Men were taller, heavier and had higher waist circumference values, compared with women. Body mass index did not significantly differ between men and women. When comparing the youngest (60-65-year-old) and the oldest ( $\geq 76$ year-old) group, gait speed declined by $21.4 \%$ in men and $27.9 \%$ in women. In both men and women, the steepest decline between ages $60-65$ years and $\geq 76$ years was observed.

Table 2 shows sex- and age- specific normative data for gait and height-normalized gait speed. In men aged 60-65 years, $66-70$ years, $71-75$ years and $\geq 76$ years, the median values were $1.38 \mathrm{~m} / \mathrm{s}, 1.30 \mathrm{~m} / \mathrm{s}, 1.22 \mathrm{~m} / \mathrm{s}$ and $1.08 \mathrm{~m} / \mathrm{s}$ for gait speed and $0.80 \mathrm{~m} / \mathrm{s}, 0.74 \mathrm{~m} / \mathrm{s}, 0.70 \mathrm{~m} / \mathrm{s}$ and $0.63 \mathrm{~m} / \mathrm{s}$ for height-normalized gait speed. In women aged 60-65 years, $66-70$ years, $71-75$ years and $\geq 76$ years, the median values were $1.41 \mathrm{~m} / \mathrm{s}, 1.27 \mathrm{~m} / \mathrm{s}, 1.08 \mathrm{~m} / \mathrm{s}$ and $0.92 \mathrm{~m} / \mathrm{s}$ for gait speed and $0.87 \mathrm{~m} / \mathrm{s}, 0.78 \mathrm{~m} / \mathrm{s}, 0.69 \mathrm{~m} / \mathrm{s}$ and $0.56 \mathrm{~m} / \mathrm{s}$ for height - normalized gait speed. Smoothed 20th, 40th, 60th and 80th percentile curves are presented in Figure 1.

In both men and women, gait speed was significantly correlated with age ( $r=-0.49$ and $-0.47, p<0.001)$, waist circumference $(r=-0.28$ and $-0.21, p<0.001)$ and body mass index $(r=-0.24$ and $-0.20, p<0.002)$. Multiple regression analysis in Table 3 showed that being women, older age and higher levels of body mass index were significantly associated with slower gait speed (multiple $\left.r=0.54, r^{2}=29.1 \%, p<0.001\right)$.

\section{Discussion}

The main purpose of the study was to establish sex- and age-normative data for gait speed and height-normalized gait speed in older men and women. Our main findings are: (1) gait speed significantly declines with age in both men and women, (2) median values for gait speed range between $1.08 \mathrm{~m} / \mathrm{s}$ and $1.38 \mathrm{~m} / \mathrm{s}$ in men and between $0.92 \mathrm{~m} / \mathrm{s}$ and $1.41 \mathrm{~m} / \mathrm{s}$ in women across the age groups and (3) being women, older age and higher body mass index values predict "slower" gait speed. 
A

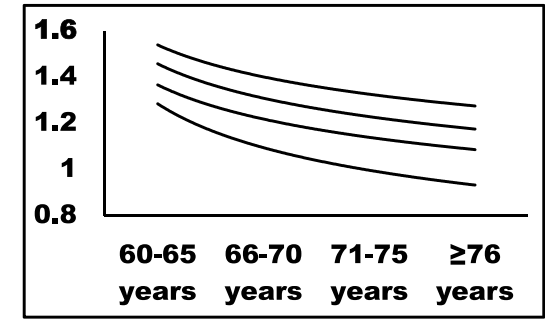

C

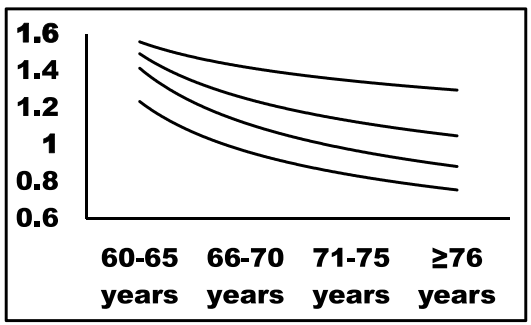

B

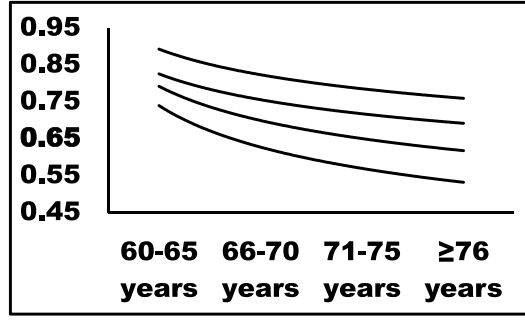

D

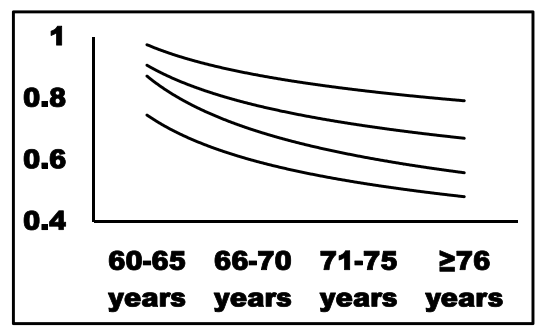

Figure I Reference curves for gait speed (A and $\mathbf{C}$ ) and height-normalized gait speed (B and $\mathbf{D})$ in men (upper row) and women (lower row).

The gait speed and height-normalized gait speed obtained in our study are consistent with previous studies conducted among older individuals, ${ }^{1,12,13}$ being around $1.30 \mathrm{~m} / \mathrm{s}$. Of note, it should be highlighted that the data obtained in this study were collected by using a pressure platform, which is a more reliable and valid method, compared to other alternative methods. ${ }^{13,16}$ Another study conducted among Japanese older adults using a pressure platform for assessing reference data of gait parameters showed, that median gait speed was 1.26 $(0.24) \mathrm{m} / \mathrm{s},{ }^{16}$ which is equal to our findings. Most recently, cut-off values of $0.88 \mathrm{~m} / \mathrm{s}$ and $0.85 \mathrm{~m} / \mathrm{s}$ have been proposed in predicting foot pain and the risk of falls in community-dwelling older women, ${ }^{20}$ pointing out that the proposed sex- and age-reference data for gait speed may serve as a potential screening tool in targeting those individuals with slower gait speed for special interventions that improve and enhance gait biomechanics.

Regarding gender differences, previous studies have shown that men walk faster, compared to women, ${ }^{1,14,17}$ which is often attributed to the larger step and stride length produced by men. When gait speed was normalized to height, our findings also showed significant differences between sexes, indicating that sex and height are in function of gait speed in this sample.

The present study also observed a significant decline in gait speed across the age groups; younger participants were faster, compared to older ones. Our findings are in line with previous ones conducted among older individuals. ${ }^{10,13,16,17}$ Specifically, Himann et $\mathrm{al}^{10}$ reported that gait speed decreased between $12 \%$ and $16 \%$ per decade after the age of 70 . In the study by Hollman et $\mathrm{al}^{13}$ gait speed did not significantly change between the ages $70-80$ yet decreased rapidly past the age of 80 .

Gait speed represents a powerful marker of health ${ }^{1}$ and walking faster is often strongly associated with a lower likelihood of developing some diseases, including allcause mortality, ${ }^{2}$ and may additionally prevent from future functional dependence, ${ }^{3}$ lower level of well-being, ${ }^{4}$ faster cognitive decline ${ }^{5}$ and frailty. ${ }^{6}$ According to previous longitudinal evidence, gait speed can predict the level of survival in older individuals. ${ }^{2}$ The mechanism between

Table 3 Predictors of Gait Speed in the Study Participants $(N=565)$

\begin{tabular}{|l|l|l|l|}
\hline Study Predictors & Unstandardized $\boldsymbol{\beta}$ & $\mathbf{9 5 \%} \mathbf{C l}$ & $\boldsymbol{p}$-value \\
\hline Sex $(\mathrm{I}=$ men; 2 = women) & -0.09 & -0.13 to -0.04 & $<0.001$ \\
Age (years) & -0.02 & -0.03 to -0.02 & $<0.001$ \\
Body mass index $\left(\mathrm{kg} / \mathrm{m}^{2}\right)$ & -0.02 & -0.02 to -0.01 & $<0.001$ \\
\hline
\end{tabular}


gait speed and lifelong independence lies in requiring energy, movement control and constant support during walking, which often reflects on multiple organ systems functioning, like musculoskeletal system or high-energy cost. $^{2}$ Also, a previous systematic review has shown that "slower" gait speed serves as a significant predictor of several adverse outcomes, including mobility disability, cognitive decline, mortality, the risk of falls and early institutionalization. ${ }^{22}$ Specifically, most of the aforementioned negative health outcomes are characteristic of older individuals walking $<0.80 \mathrm{~m} / \mathrm{s}$ at the usual pace, pointing out that such a threshold is "easy-to-remember" and should be used in clinical trials as exclusion/inclusion criteria or as an outcome. ${ }^{22}$ In that way, measuring gait speed should be used in health-related settings for obtaining an extra predictor of overall health in older individuals.

This study is not without limitations. First, by using a cross-sectional design, the causality of the association between sex, age and gait speed cannot be determined. Second, selection bias could be possible, since participants volunteered in the study and came to measurements by themselves. ${ }^{16}$ Third, we did not collect additional gait performance information, like spatial or temporal parameters strongly associated with gait speed. ${ }^{16}$ By providing such information, we could have made the relations between walking speed at the usual pace and the risk of falls. Finally, participants walked barefoot across the pressure platform. In barefoot walking, step length is larger, stance duration is shorter, and cadence is higher than in walking while wearing standard shoes. ${ }^{16,23}$

\section{Conclusions}

This is the first examining gait speed and heightnormalized gait speed in a sample of Croatian communitydwelling older individuals by using a pressure platform. Although gait speed reference values have been widely established, newly proposed values for Croatian older adults should serve for gait assessment in both clinical and community-dwelling settings.

\section{Data Sharing Statement}

All the data are freely available upon reasonable request from the corresponding author.

\section{Ethics Approval}

Approved by the University of Zagreb and Ethical Committee of the Faculty of Kinesiology.

\section{Consent to Participate}

Written consent was obtained.

\section{Acknowledgments}

We would like to thank all the study participants for their enthusiastic participation in the study.

\section{Author Contributions}

All authors made substantial contributions to conception and design, acquisition of data, or analysis and interpretation of data; took part in drafting the article or revising it critically for important intellectual content; agreed to submit to the current journal; gave final approval of the version to be published; and agree to be accountable for all aspects of the work.

\section{Funding}

This research did not receive any specific grant from funding agencies in the public, commercial, or not-forprofit sectors.

\section{Disclosure}

The authors report no conflicts of interest in this work.

\section{References}

1. Bohannon RW. Comfortable and maximum walking speed of adults aged 20-79 years: reference values and determinants. Age Aging. 1997;26:15-19. doi:10.1093/ageing/26.1.15

2. Studenski S, Perera $\mathrm{S}$, Patel K, et al. Gait speed and survival in older adults. JAMA. 2011;305:50-58. doi:10.1001/jama.2010.1923

3. Shinkai S, Watanabe S, Kumagai S, et al. Walking speed as a good predictor for the onset of functional dependence in a Japanese rural community population. Age Ageing. 2000;29:441-446. doi:10.1093/ ageing/29.5.441

4. Cesari M. Role of gait speed in the assessment of older patients. JAMA. 2011;305:93-94. doi:10.1001/jama.2010.1970

5. Dumurgier J, Artaud F, Touraine C, et al. Gait speed and decline in gait speed as predictors of incident dementia. J Gerontol a Biol Sci Med Sci. 2017;72:655-661. doi:10.1093/gerona/glw110

6. Montero - Odasso M, Muir SW, Hall M, et al. Gait variability is associated with frailty in community-dwelling older adults. J Gerontol a Biol Sci Med Sci. 2011;66:568-576. doi:10.1093/gerona/glr007

7. Bassey EJ, Bendall MJ, Pearson M. Muscle strength in the triceps surae and objectively measured customary walking activity in men and women over 65 years of age. Clin Sci. 1988;74(1):85-89. doi:10.1042/cs0740085

8. Dobbs RJ, Charlett A, Bowes SG, et al. Is this walk normal. Age Ageing. 1993;22:27-30. doi:10.1093/ageing/22.1.27

9. Cunningham DA, Rechnitzer PA, Pearce ME, Donner AP. Determinants of self-selected walking pace across ages 19 to 66 . $J$ Gerontol. 1982;37:560-564. doi:10.1093/geronj/37.5.560

10. Himann JE, Cunningham DA, Rechnitzer PA, Paterson DH. Age related changes in speed of walking. Med Sci Sports Exerc. 1988;20:161-166. doi:10.1249/00005768-198820020-00010 
11. Oberg T, Karsznia A, Oberg K. Basic gait parameters: reference data for normal subjects. 10-79 years of age. $J$ Rehabil Res. 1993;30:210-223.

12. Bohannon RW, Andrews AW, Thomas MW. Walking speed: reference values and correlates for older adults. J Orthop Sports Phys Ther. 1996;24:86-90. doi:10.2519/jospt.1996.24.2.86

13. Hollman JH, McDade EM, Petersen RC. Normative spatiotemporal gait parameters in older adults. Gait Posture. 2011;34:111-118. doi:10.1016/j.gaitpost.2011.03.024

14. Seino S, Shinkai S, Fujiwara Y, et al. Reference values and age and sex differences in physical performance measures for community dwelling older Japanese: a pooled analysis of six cohort studies. PLoS One. 2014;9:e99487. doi:10.1371/journal.pone.0099487

15. Taniguchi Y, Watanabe Y, Osuka Y, et al. Characteristics for gait parameters of community - dwelling elderly Japanese with lower cognitive function. PLoS One. 2019;14:e0212646. doi:10.1371/journal.pone. 0212646

16. Kawai H, Taniguchi Y, Seino S, et al. Reference values of gait parameters measured with a plantar pressure platform in community-dwelling older Japanese adults. Clin Interv Aging. 2019;14:1265-1276. doi:10.2147/CIA.S213216
17. McKay MJ, Baldwin JN, Ferreira P, et al. Spatiotemporal and plantar pressure patterns of 1000 healthy individuals aged 3-101 years. Gait Posture. 2017;58:78-87. doi:10.1016/j.gaitpost.2017.07.004

18. United Nations Population Division. World Population Aging, $1950-$ 2050. New York; 2002.

19. Murgić J, Jukić T, Tomek - Roksandić S, Ljubičić M, Kusić Z. The aging of Croatian population. Coll Antropol. 2009;2:701-705.

20. Štefan L, Kasović M, Zvonar M. Gait speed as a screening tool for foot pain and the risk of falls in community-dwelling older women: a cross-sectional study. Clin Int Aging. 2020;15:1569-1574. doi:10.2147/CIA.S260931

21. Cole TJ. The LMS method for constructing normalized growth standards. Eur J Clin Nutr. 1990;44:45-60.

22. Abellan van Kan G, Rolland Y, Andrieu S, et al. Gait speed at usual pace as a predictor of adverse outcomes in community-dwelling older people an International Academy on Nutrition and Aging (IANA) task force. J Nutr Health Aging. 2009;13(10):881-889. doi:10.1007/ s12603-009-0246-z

23. Broscheid $\mathrm{KC}$, Zech A. Influence of barefoot, minimalist, and standard footwear conditions on gait and balance in healthy older adults. J Am Geriatr Soc. 2016;64:435-437. doi:10.1111/jgs.13980
Clinical Interventions in Aging

\section{Publish your work in this journal}

Clinical Interventions in Aging is an international, peer-reviewed journal focusing on evidence-based reports on the value or lack thereof of treatments intended to prevent or delay the onset of maladaptive correlates of aging in human beings. This journal is indexed on PubMed Central, MedLine, CAS, Scopus and the Elsevier

\section{Dovepress}

Bibliographic databases. The manuscript management system is completely online and includes a very quick and fair peer-review system, which is all easy to use. Visit http://www.dovepress.com/ testimonials.php to read real quotes from published authors. 